\title{
Determinan Persalinan Prematur di RSUD Dr. Abdul Moeloek
}

\author{
Eliza $^{1}$, Dina Dwi Nuryani ${ }^{2}$, Rosmiyati ${ }^{3}$ \\ ${ }^{1,2,3}$ Fakultas Kesehatan Masyarakat, Universitas Malahayati \\ Email: elizaeko888bdl@gmail.com
}

\begin{abstract}
The Determinant of Premature Labor in RSUD. Dr. Abdul Moeloek. Infant mortality in Indonesia around 56\% occurs in the very early period of a neonatal period or newborn. Most of the neonatal deaths occur at the age of 0-6 days (78.5\%) and prematurity is the major cause of neonatal death. Based on perinatology room report of Dr. H. Abdul Moeloek hospital in 2015, there were 77 premature births from 391 labors. This number then increased to 84 premature labor from 402 labors by 2016 . The objective of this research was to identify the determinants that influenced premature labor in a hospital. H. Abdul Moeloek 2012-2016. This was a quantitative research, design of analytic research was through case control research method. The population was whole pregnant mothers who had premature labor in Dr. H. Abdul Moeloek hospital 20122016. The sample was 62 cases and 62 controls to become 138 people. The analysis was through chi-square test. Multivariate analysis used regression logistic. The result showed that there was a significant correlation between mothers' age ( $p$-value $=0,048)$, parity ( $p$-value $=0,000)$, pregnancy complication $(\mathrm{p}$-value $=0,000), \operatorname{KPD}(\mathrm{p}$-value $=0,005)$ and mothers education level $(\mathrm{p}$-value = $0,011)$. The result of the multivariate analysis showed that the most dominant factor towards premature labor was pregnancy complication ( $\mathrm{p}$-value $=0,000$ ). The importance of pregnant mothers to make an antenatal care visit in accordance with government program so that abnormalities or complication in pregnancy can be earlier detected.
\end{abstract}

Keywords: Premature labor, Complication of pregnancy

\begin{abstract}
Abstrak: Determinan Persalinan Prematur di RSUD Dr. Abdul Moeloek. Kematian bayi di Indonesia sekitar 56\% terjadi pada periode sangat dini yaitu di masa neonatal atau bayi baru lahir. Sebagian besar kematian neonatal terjadi pada usia 0-6 hari $(78,5 \%)$ dan prematuritas merupakan penyebab utama kematian neonatal. Berdasarkan laporan ruang perinatologi RSUD. Dr. Abdul Moeloek Pada tahun 2015 terdapat 77 persalinan prematur dari 391 persalinan. Jumlah ini kemudian meningkat menjadi 84 persalinan prematur dari 402 persalinan pada tahun 2016. Penelitian ini bertujuan untuk mengetahui determinan yang mempengaruhi persalinan prematur di RSUD. Dr. Abdul Moeloek tahun 2012-2016. Jenis penelitian kuantitatif desain penelitian analitik menggunakan metode penelitian Case Control. Populasi dalam penelitian ini adalah seluruh ibu hamil yang mengalami prematur di rumah sakit Dr.H.AbdoelMoeloek tahun 2012-2016. Sampel penelitian ini adalah sebanyak 62 kasus dan 62 kontrol menjadi 138 orang. Analisis menggunakan ujiChi-Square. Analisis Multivariat menggunakan regresi logistik. Hasil analisis menunjukkan bahwa terdapat hubungan yang bermakna antara usia ibu ( $p$-value $=0,048)$, paritas ( $p$-value $=0,000)$, komplikasi kehamilan ( $p$-value $=0,000)$, KPD ( $p$-value $=0,005)$ dan tingkat pendidkan ibu $(p$ value $=0,011)$. Perlunya ibu hamil melakukan kunjungan antenatal care sesuai program pemerintah agar kelainan ataupun komplikasi dalam kehamilan dapat terdeteksi lebih awal.
\end{abstract}

Kata kunci: Persalinan prematur, Komplikasi kehamilan

Situasi kesehatan ibu dan bayi di negara berkembang termasuk Indonesia masih memprihatinkan. Angka kematian Ibu (228/100.000 kelahiran hidup) di Indonesia masih tergolong tinggi, demikian juga dengan angka kematian bayi (34/1000 kelahiran hidup). Bahkan jika dibandingkan dengan negara-negara di wilayah Asia Tenggara, situasi di Indonesia masih berada di bawah Singapura, Malaysia, dan Brunei; setara dengan Filipina, Thailand dan Vietnam serta sedikit lebih baik dibanding Myanmar, Laos dan Kamboja (Fikawati \&
Syafiq, 2015). World Health Organization (WHO) menyatakan kematian bayi dengan fenomena $2 / 3$ yaitu $2 / 3$ kematian bayi ( $0-1$ tahun) terjadi pada masa neonatal (0-28 hari), 2/3 kematian neonatal terjadi pada masa perinatal ( 0 7 hari) dan 2/3 kematian perinatal terjadi pada hari pertama (Depkes RI, 2006).

Kematian bayi di Indonesia sekitar $56 \%$ terjadi pada periode sangat dini yaitu di masa neonatal atau bayi baru lahir. Sebagian besar kematian neonatal terjadi pada usia 0-6 hari 
$(78,5 \%)$ dan prematuritas merupakan penyebab utama kematian neonatal (Kemenkes RI, 2011).

Definisi persalinan prematur menurut WHO adalah lahirnya bayi sebelum kehamilan berusia lengkap 37 minggu (Krisnadi, 2009). Bayi lahir prematur umumnya lebih disebabkan oleh komplikasi kehamilan yang membuat kandungan ibu dalam rahim lemah sehingga janin harus segera dilahirkan (Fikawati \& Syafiq, 2015).

Bayi prematur terutama yang lahir dengan usia kehamilan <32 minggu, mempunyai risiko kematian 70 kali lebih tinggi,karena mereka mempunyai kesulitan untuk beradaptasi dengan kehidupan di luar rahim akibat ketidakmatangan sistem organ tubuhnya seperti paru-paru, jantung, ginjal, hati dan sistem pencernaannya (Krisnadi, 2009).

Bayi kurang bulan atau prematur biasanya mengalami penyulit dan memerlukan perawatan yang memadai (Kemenkes RI, 2011). Karakteristik prematuritas pada sebuah kehamilan akan di picu oleh karakteristik pasien dengan status sosio ekonomi yang rendah termasuk di dalamnya penghasilan rendah, pendidikan yang rendah sehingga mempengaruhi pola nutrisi yang rendah; umur kehamilan pada usia 16 tahun dan primigravida >30 tahun; riwayat pernahirkn prematur; pekerjaan fisik yang berat, tekanan mental (stress) atau kecemasan yang tinggi dapat meningkatkan kejadian prematur, merokok lebih dari 10 batang sehari; penggunaan obat bius/kokain (Rukiyah \& Yulianti, 2010).

Kejadian prematur berbeda pada setiap negara, di negara maju, misalnya di Eropa, angkanya berkisar antara 5-11\%. Di USA, sekitar satu dari sembilan bayi dilahirkan prematur $(11,9 \%)$ dan di Australia kejadiannya sekitar $7 \%$. Di negara yang sedang berkembang angka kejadiannya masih jauh lebih tinggi (Krisnadi,2009).

Beberapa faktor mempunyai andil dalam terjadinya persalinan prematur/prematur seperti faktor pada ibu, faktor janin dan plasenta, ataupun faktor lain seperti sosioekonomik (Winkjosastro, 2014). Beberapa faktor penyebab akan menambah keadaan prematuritas antara lain : infeksi saluran kemih, penyakit ibu seperti hipertensi dalam kehamilan, asma, penyakit jantung, kecanduan obat, kolestatis, anemia, keadaan yang menyebabkan distensi uterus berlebihan yaitu kehamilan multiple, hidramnion, diabetes, isoimunisasi $\mathrm{Rh}$, peradarahan antepartum, infeksi umum pada ibu, tindakan bedah selama kehamilan, kehamilan dengan AKDR (Rukiyah \& Yulianti, 2010).
Permasalahan yang terjadi pada persalinan prematur bukan saja pada kematian perinatal, melainkan bayi prematur ini sering pula disertai dengan kelainan, baik kelainan jangka pendek maupun jangka panjang. Kelainan jangka pendek yang sering terjadi adalah: RDS (Respiratory Distress Syndrome), perdarahan intra/ periventrikular, NEC (Necrotizing Entero Cilitis), displasi bronko-pulmonar, sepsis, dan paten duktus arteriosus (Winkjosastro, 2014).

Komplikasi jangka pendek pada bayi prematur selalu dikaitkan dengan pematangan paru janin yang belum sempurna. Bayi-bayi yang lahir pada usia hamil 23-24 minggu yang berhasil diselamatkan menunjukkan komplikasi kelainan otak yang cukup berarti (79\% atau lebih). Sebagian besar komplikasi dapat dicegah dan ditangani antara lain bila tenaga kesehatan mampu mengidentifikasi dini komplikasi serta pelayanan emergency di rumah sakit dilaksanakan secara cepat dan tepat guna (Kemenkes RI, 2015). Adapun kelainan jangka panjang sering berupa kelainan neurologik seperti cerebral palfsi, retinopati, retardasi mental, juga dapat terjadi disfungsi neurobehavioral dan prestasi sekolah yang kurang baik. Sisi lain yang harus diperhatikan dalam menangani bayi prematur terutama bayi dengan berat lahir sangat rendah $(<1.500$ gram), yaitu biaya yang sangat mahal dan meminta tenaga yang banyak (Winkjosastro, 2014).

Di Indonesia kematian bayi sekitar $56 \%$ terjadi pada periode sangat dini yaitu di masa neonatal atau bayi baru lahir dan sebagian besar kematian neonatal terjadi pada usia 0-6 hari $(78,5 \%)$ dan prematuritas merupakan penyebab utama kematian neonatal.

Di provinsi lampung sendiri untuk Angka kematian bayi berdasarkan data SDKI meskipun trendnya menunjukkan kecenderungan menurun yaitu dari 55 per $1000 \mathrm{KH}$ tahun 2002 menjadi 30 per 1000 kelahiran hidup, namun angka ini bila dibandingkan dengan target dari MDGs tahun 2015 sbesar 23 per 1000 kelahiran hidup maka target penurunan angka kematian bayi belum tercapai. Untuk penyebab kematian bayi terbesar disebabkan oleh BBLR dan prematuritas (Profil Dinkes lampung 2013).

RSUD Dr. Abdul Moeloek merupakan rumah sakit pusat rujukan di Provinsi Lampung. Berdasarkan laporan ruang perinatologi RSUD. Dr. Abdul Moeloek Pada tahun 2015 terdapat 77 persalinan prematur dari 391 persalinan. Jumlah ini kemudian meningkat menjadi 84 persalinan prematur dari 402 persalinan pada tahun 2016 . Karena tingginya jumlah persalinan prematur di rumah sakit pusat rujukan ini serta dampak yang 
ditimbulkan bayi prematur tersebut sehingga peneliti tertarik untuk meneliti faktor-faktor yang mempengaruhi persalinan prematur di RSUD Dr. Abdul Moeloektahun 2012-2016. Desain penelitian ini menggunakan desain penelitian case control. Tujuan penelitian adalah untuk diketahui faktor-faktor yang mempengaruhi persalinan prematur di RSUD Dr. Abdul Moeloek tahun 2012-2016.

\section{METODE}

Penelitian ini merupakan analisis terhadap data sekunder rekam medis di RSUD. Dr. Abdul Moeloek tahun 2016 yang dilakukan dengan mengumpulkan informasi mengenai riwayat kehamilan dan persalinan responden terpilih selama kurun waktu Januari-Desember 20122016.

Jenis penelitian ini merupakan penelitian kuantitatif dengan desain penelitian case control yaitu studi observasional untuk mengetahui satu atau lebih faktor merupakan faktor risiko dari satu situasi masalah (Lapau, 2012). Penelitian ini dilakukan di RSUD Dr. Abdul Moeloek pada bulan Mei s.d Juni 2017. Rancangan penelitian ini adalah analitik case control. Rancangan ini dipilih dengan pertimbangan dapat digunakan untuk mencari hubungan seberapa jauh faktor risiko mempengaruhi terjadinya penyakit atau kelainan tertentu. Kekuatan hubungan sebab akibat desain kasus kontrol lebih kuat dibandingkan dengan cross sectional study, biasanya murah, cepat memberikan hasil dan tidak memerlukan sampel yang besar.

Populasi kasus dalam penelitian ini adalah seluruh ibu bersalin dengan persalinan prematur di RSUD Dr. Abdul Moeloek tahun 2012-2016. Populasi kontrol dalam penelitian ini adalah seluruh ibu bersalin dengan persalinan aterm di RSUD Dr. Abdul Moeloektahun 2012-2016. Jumlah seluruh persalinan aterm di RSUD Dr. Abdul Moeloek tahun 2012-2016 sebanyak 6102 persalinan. Sampel pada kelompok kasus dalam penelitian ini adalah sebagian ibu bersalin dengan persalinan prematur di RSUD Dr. Abdul Moeloektahun 2012-2016. Sampel pada kelompok kontrol dalam penelitian ini adalah sebagian ibu bersalin dengan persalinan aterm di RSUD Dr. Abdul Moeloek tahun 2012-2016. Berdasarkan perhitungan sampel diperoleh jumlah sampel minimal dalam satu kelompok sebanyak 62 kasus. Pengambilan sampel dilakukan melalui random sampling.Kemudian peneliti membuat perbandingan jumlah kasus dan kontrol yaitu 1 : 1 sehingga diperoleh sampel 62pada kelompok kasus dan 62sampel pada kelompok kontrol. Total sampel pada penelitian ini adalah 124 sampel.

\section{HASIL}

Tabel 1. Distribusi frekuensi Responden dengan Persalinan Prematur

\begin{tabular}{lcccc}
\hline \multirow{2}{*}{ Variabel } & \multicolumn{2}{c}{ Kasus } & \multicolumn{2}{c}{ Kontrol } \\
\cline { 2 - 5 } & $\mathbf{n}$ & $\mathbf{\%}$ & $\mathbf{n}$ & $\mathbf{\%}$ \\
\hline Umur Ibu & & & & \\
$\quad 16$ tahun/>35 tahun & 35 & 56,5 & 23 & 37,1 \\
$16-35$ tahun & 27 & 43,5 & 39 & 62,9 \\
\hline Paritas & & & & \\
1 atau $\geq 4$ & 41 & 66,1 & 19 & 30,6 \\
2-3 & 21 & 33,9 & 43 & 69,4 \\
\hline Komplikasi Kehamilan & & & & \\
Ada & 52 & 83,9 & 18 & 29,0 \\
Tidak & 10 & 16,1 & 44 & 71,0 \\
\hline Ketuban pecah dini & & & & \\
Ada & 15 & 24,2 & 3 & 4,8 \\
Tidak & 47 & 75,8 & 59 & 95,2 \\
\hline Tingkat Pendidikan & & & & \\
Rendah & 34 & 54,8 & 19 & 30,6 \\
Tinggi & 28 & 45,2 & 43 & 69,4 \\
\hline
\end{tabular}

\section{Tabel 2. Determinan Persalinan Prematur}

\begin{tabular}{|c|c|c|c|c|c|c|}
\hline \multirow{2}{*}{$\begin{array}{c}\text { Variabel } \\
\text { Independen }\end{array}$} & \multicolumn{2}{|c|}{ Prematur } & \multicolumn{2}{|c|}{ Aterm } & \multirow{2}{*}{$\begin{array}{c}\text { OR } \\
(95 \% \\
\text { CI })\end{array}$} & \multirow{2}{*}{$\begin{array}{c}p- \\
\text { value }\end{array}$} \\
\hline & n & $\%$ & $\mathbf{n}$ & $\%$ & & \\
\hline $\begin{array}{l}\text { Usia Ibu } \\
<16 \text { thn/ }>35 \\
\text { thn } \\
16-35 \text { thn }\end{array}$ & $\begin{array}{l}35 \\
27 \\
\end{array}$ & $\begin{array}{l}56,5 \\
43,5 \\
\end{array}$ & $\begin{array}{l}23 \\
39 \\
\end{array}$ & $\begin{array}{l}37,1 \\
62,9 \\
\end{array}$ & $\begin{array}{r}2,198 \\
(1,071- \\
4,531) \\
\end{array}$ & 0,008 \\
\hline $\begin{array}{l}\text { Paritas } \\
1 \text { atau } \geq 4 \\
2-3\end{array}$ & $\begin{array}{l}41 \\
21\end{array}$ & $\begin{array}{l}66,1 \\
33,9\end{array}$ & $\begin{array}{l}19 \\
43\end{array}$ & $\begin{array}{l}30,6 \\
69,4\end{array}$ & $\begin{array}{r}4,419 \\
(2,079- \\
9,389)\end{array}$ & 0,000 \\
\hline $\begin{array}{l}\text { Komplikasi } \\
\text { kehamilan } \\
\text { Ada } \\
\text { Tidak } \\
\end{array}$ & $\begin{array}{l}52 \\
10 \\
\end{array}$ & $\begin{array}{l}83,9 \\
16,1\end{array}$ & $\begin{array}{l}18 \\
44\end{array}$ & $\begin{array}{l}29,0 \\
71,0\end{array}$ & $\begin{array}{r}12,711 \\
(5,320 \\
- \\
30,372)\end{array}$ & 0,000 \\
\hline $\begin{array}{l}\text { Ketuban } \\
\text { pecah dini } \\
\text { Ada } \\
\text { Tidak }\end{array}$ & $\begin{array}{l}15 \\
47 \\
\end{array}$ & $\begin{array}{l}24,2 \\
75,8\end{array}$ & $\begin{array}{r}3 \\
59 \\
\end{array}$ & $\begin{array}{r}4,8 \\
95,2 \\
\end{array}$ & $\begin{array}{r}6,277 \\
(1,715- \\
22,972)\end{array}$ & 0,005 \\
\hline $\begin{array}{l}\text { Tingkat } \\
\text { pendidikan } \\
\text { Rendah } \\
\text { Tinggi }\end{array}$ & $\begin{array}{l}34 \\
28\end{array}$ & $\begin{array}{l}54,8 \\
45,2\end{array}$ & $\begin{array}{l}19 \\
43\end{array}$ & $\begin{array}{l}30,6 \\
69,4\end{array}$ & $\begin{array}{c}2,748 \\
(1,316- \\
5,737)\end{array}$ & 0,011 \\
\hline
\end{tabular}

\section{PEMBAHASAN}

\section{Hubungan Usia dengan Persalinan Prematur}

Pada hasil analisis bivariat menunjukkan bahwa sebanyak $35(56,5 \%)$ ibu hamil usia <16 tahun/ >35 tahun mengalami persalinan prematur, dan sebanyak $27(43,5 \%)$ ibu hamil dengan usia 
16-35 tahun mengalami persalinan prematur. Hasil uji statistik didapatkan nilai $p=0,048$ $(p<0,05)$ yang artinya secara statistik terdapat hubungan yang bermakna antara usia ibu dengan persalinan prematur. Dari hasil analisis diperoleh nilai OR sebesar 2,198 (95\% CI: $1,071-4,513)$ yang artinya ibu hamil dengan usia $<16$ tahun/ $>35$ tahun berisiko 2,198 kali lebih tinggi untuk mengalami persalinan prematur dibandingkan dengan ibu hamil dengan usia 16-35 tahun.

Menurut pendapat peneliti secara fisik alat reproduki pada usia $<20$ tahun belum terbentuk sempurna, pada umumnya rahim masih relatif kecil karena pembentukan belum sempurna dan pertumbuhan tulang panggul belum belum cukup lebar. Pada usia <20 tahun kondisi ibu juga masih dalam tahap pertumbuhan sehingga masukan makanan banyak dipakai untuk ibu sehingga mengakibatkan gangguan pertumbuhan janin. Sedangkan pada usia $>35$ tahun risiko terjadinya komplikasi kehamilan juga meningkat yang berdampak pada morbiditas dan mortalitas bayi yang akan dilahirkan.

\section{Hubungan Paritas dengan Persalinan Prematur}

Pada hasil analisis bivariat menunjukkan bahwa bahwa sebanyak $41(66,1 \%)$ ibu hamil dengan paritas 1 atau $\geq 4$ mengalami persalinan prematur dan sebanyak $21(33,9 \%)$ ibu hamil dengan paritas 2-3 mengalami persalinan prematur. Hasil uji statistik didapatkan nilai $p=0,000(p<0,05)$ yang artinya secara statistik terdapat hubungan yang bermakna antara paritas dengan persalinan prematur. Dari hasil analisis diperoleh nilai OR sebesar 4,419 (95\% CI: 2,079$9,389)$ yang artinya ibu hamil dengan paritas 1 atau $\geq 4$ berisiko 4,419 kali lebih tinggi untuk mengalami persalinan prematur dibandingkan dengan ibu hamil dengan paritas 2-3.

Menurut pendapat peneliti pada paritas 1 atau primigravida resiko ibu mengalami komplikasi preeklampsia dan eklampsia lebih tinggi, sedangkan preeklampsia-eklampsia merupakan salah satu komplikasi kehamilan yang berdampak pada morbiditas dan mortalitas dari ibu maupun bayi yang yang akan dilahirkan. Komplikasi yang dialami oleh ibu seperti preeklampsia-eklampsia cenderung menyebabkan kehamilan harus diterminasi sehingga meningkatkan risiko untuk terjadinya persalinan preterm.

\section{Hubungan Komplikasi dengan Persalinan Prematur}

Pada hasil analisis bivariat menunjukkan bahwa sebanyak $52(83,9 \%)$ ibu hamil dengan komplikasi kehamilan mengalami persalinan prematur, dan sebanyak $10(16,1 \%)$ ibu hamil tanpa komplikasi kehamilan mengalami persalinan prematur. Hasil uji statistik didapatkan nilai $p=0,004 \quad(p<0,05)$ yang artinya secara statistik terdapat hubungan yang bermakna antara komplikasi kehamilan dengan persalinan prematur. Dari hasil analisis diperoleh nilai OR sebesar 12,711 (95\% CI: 5,320-30,372) yang artinya ibu hamil dengan komplikasi kehamilan berisiko 12,711 kali lebih tinggi untuk mengalami persalinan prematur dibandingkan dengan ibu hamil tanpa komplikasi kehamilan.

Menurut pendapat peneliti komplikasi kehamilan merupakan salah satu faktor yang menyebabkan kejadian persalinan prematuritas dalam penelitian ini antara lain disebabkan karena jumlah responden dengan komplikasi kehamilan pada kelompok ibu hamil yang mengalami persalinan prematur dalam penelitian ini cukup tinggi. Selain itu komplikasi yang dialami oleh ibu selama kehamilan akan berdampak pada morbiditas dan mortalitas dari bayi yang yang akan dilahirkan. Komplikasi yang dialami oleh ibu seperti preeklampsia-eklampsia cenderung menyebabkan kehamilan harus diterminasi sehingga meningkatkan risiko untuk terjadinya persalinan prematur.

\section{Hubungan Ketuban Pecah Dini dengan Persalinan Prematur}

Pada hasil analisis bivariat menunjukkan bahwa sebanyak $15(24,2 \%)$ ibu hamil dengan ketuban pecah dini mengalami persalinan prematur, dan sebanyak $47(75,8 \%)$ ibu hamil yang tidak mengalami ketuban pecah dini mengalami persalinan prematur. Hasil uji statistik didapatkan nilai $p=0,005(p<0,05)$ yang artinya secara statistik terdapat hubungan yang bermakna ketuban pecah dini dengan persalinan prematur. Dari hasil analisis diperoleh nilai OR sebesar 6,277 (95\% CI: 1,715-22,972) yang artinya ibu hamil dengan ketuban pecah dini berisiko 6,277 kali lebih tinggi untuk mengalami persalinan prematur dibandingkan dengan ibu hamil tanpa riwayat ketuban pecah dini.

Menurut peneliti komplikasi KPD dapat mengarah pada persalinan prematur. Hal ini akan meningkatkan risiko pretermitas dan komplikasi perinatal serta neonatal, sehingga perlu ibu hamil untuk mengenal penanganan KPD karena 
diagnosisi yang cepat dan penanganan yang adekuat dapat menyelamatkan janin.

\section{Hubungan Tingkat Pendidikan Ibu dengan Persalinan Preterm}

Pada hasil analisis bivariat menunjukkan bahwa sebanyak $34(54,8 \%)$ ibu hamil dengan tingkat pendidikan rendah mengalami persalinan prematur, dan sebanyak $28(45,2 \%)$ ibu hamil dengan tingkat pendidikan tinggi mengalami persalinan prematur. Hasil uji statistik didapatkan nilai $p=0,011 \quad(p<0,05)$ yang artinya secara statistik terdapat hubungan yang bermakna tingkat pendidikan ibu dengan persalinan prematur. Dari hasil analisis diperoleh nilai OR sebesar 2,748 (95\% CI: 1,316-5,737) yang artinya ibu hamil dengan tingkat pendidikan rendah berisiko 2,748 kali lebih tinggi untuk mengalami persalinan preterm dibandingkan dengan ibu hamil dengan dengan tingkat pendidikan tinggi.

Menurut pendapat peneliti tingkat pendidikan ibu yang rendah akan mempengaruhi pola pikir ibu dan keputusan yang ibu ambil terhadap kesehatannya. Karena dengan tingkat pendiidikan ibu tinggi, ibu akan memahami langkah-langkah yang dapat dilakukan untuk menjaga kehamilannya antara lain pentingnya pemeriksaan kehamilan yang sesuai dengan standar untuk memproteksi dini terjadinya kelainan dalam kehamilannya sehingga mendapatkan intervensi yang tepat lebih awal.

\section{SIMPULAN}

Berdasarkan analisis dan pembahasan yang telah dijabarkan pada bab 4 maka dapat diambil kesimpulan yaitu:
1. Distribusi frekuensi responden dalam penelitian ini yaitu sebanyak $58(46,8 \%)$ ibu hamil dengan usia <16 tahun/ >35 tahun, sebanyak $60(48,4 \%)$ ibu dengan paritas 1 atau $>4$, sebanyak $24(19,4 \%)$ ibu hamil dengan jarak kehamilan $<24$ atau $>36$ bulan, sebanyak $11 \quad(8,9 \%)$ ibu hamil dengan riwayat kehamilan sebelumnya berisiko, sebanyak 70 (56,5\%) ibu hamil dengan komplikasi kehamilan, sebanyak 18 (14,5\%) ibu hamil dengan ketuban pecah dini dan sebanyak 53 (42,7\%)ibu hamil dengan tingkat pendidikan rendah.

2. Ada hubungan antara usia ibu dengan persalinan prematur ( $p$-value $=0,048)$, paritas $(p$-value $=0,000)$, komplikasi kehamilan $(p$ value $=0,000)$, ketuban pecah dini $(p$ value $=0,005)$ dan tingkat pendidkan ibu $(p$ value $=0,011$ ).

3. Ada hubungan antara paritas dengan persalinan prematur $(p$-value $=0,000)$

4. Ada hubungan yang bermakna antara komplikasi kehamilan dengan persalinan prematur ( $p$-value $=0,000$ ).

5. Ada hubungan antara ketuban pecah dini dengan persalinan prematur ( $p$-value $=0,005)$.

6. Ada hubungan antara tingkat pendidkan ibu dengan persalinan prematur $(p$-value $=0,011)$.

\section{SARAN}

Perlunya peningkatan penyuluhan dan konseling oleh tenaga kesehatan di tingkat pelayanan kesehatan primer baik puskesmas, klinik bersalin maupun bidan praktek swasta kepada ibu hamil terutama ibu hamil dengan komplikasi kehamilan agar melakukan kunjungan antenatal care sesuai program pemerintah agar kelainan ataupun komplikasi dalam kehamilan dapat terdeteksi lebih awal.

\section{DAFTAR PUSTAKA}

Fikawati \& Syafiq. 2015. Gizi Ibu dan Bayi. Jakarta: PT. Raja Grafindo Persada.

Kementerian Kesehatan RI. 2011. Buku Pedoman Pengenalan Tanda Bahaya pada Kehamilan, Persalinan dan Nifas. Jakarta

Kementerian Kesehatan RI. 2015. Pedoman Audit maternal perinatal (AMP). Jakarta.

Krisnaldi. 2009. Persalinan Prematur. Jakarta: Penerbit Buku Kedokteran EGC.
Lapau. 2012. Metode Penelitian Kesehatan, Metode Ilmiah Penulisan Skripsi, Tesis dan Disertasi. Jakarta: Penerbit Yayasan Pustaka Obor Indonesia.

Rukiyah \& Yulianti. 2010. Asuhan Kebidanan (Patologi Kebidanan). Jakarta: Trans Info Media.

Winkjosastro. 2014. Ilmu Kebidanan. Jakarta: Yayasan Bina Pustaka Sarwono Prawirohardjo. 